\title{
Formation of nanocrystals based on decomposition in the amorphous $\mathrm{Zr}_{41.2} \mathrm{Ti}_{13.8} \mathrm{Cu}_{12.5} \mathrm{Ni}_{10} \mathrm{Be}_{22.5}$ alloy
}

\author{
S. Schneider ${ }^{\text {a) }}$ \\ 1. Physikalisches Institut and Sonderforschungsbereich 345, Universitäet Göettingen, 37073 Göettingen, \\ Germany \\ P. Thiyagarajan \\ Argonne National Laboratory, Argonne, Illinois 60439
}

W. L. Johnson

W. M. Keck Laboratory of Engineering Materials, California Institute of Technology, Pasadena, California 91125

(Received 20 September 1995; accepted for publication 14 November 1995)

\begin{abstract}
Primary crystallization and decomposition in the bulk amorphous alloy $\mathrm{Zr}_{41.2} \mathrm{Ti}_{13.8} \mathrm{Cu}_{12.5} \mathrm{Ni}_{10} \mathrm{Be}_{22.5}$ have been studied by small angle neutron scattering (SANS), transmission electron microscopy (TEM), and differential scanning calorimetry (DSC). SANS data of samples annealed isothermally at $623 \mathrm{~K}$ exhibit an interference peak centered at $q=0.46 \mathrm{~nm}^{-1}$ after an incubation time of about $100 \mathrm{~min}$. TEM and DSC investigations confirm that the respective periodic variation in the scattering length density is due to the formation of nanocrystals embedded in the amorphous matrix. These observations suggest that during the incubation time a chemical decomposition process occurs and the related periodic composition fluctuations give rise to the observed periodic arrangement of the nanocrystals. (C) 1996 American Institute of Physics. [S0003-6951(96)04804-2]
\end{abstract}

In metallic glasses, crystallization and decomposition have been observed in undercooled liquids during cooling from the melt as well as during reheating experiments. ${ }^{1-3}$ Phase separation requires diffusivity of the atomic species over several interatomic distances and at least two local minima of the Gibbs free energy versus composition function. In multicomponent alloys a large difference in the heat of mixing of the constitutive binary liquids can act as a thermodynamical driving force for phase separation. ${ }^{4}$ In these systems the nucleation of crystalline phases is more difficult than for conventional binary metallic glasses, as expressed by the "Confusion Principle." 5

Recently, a unique family of multicomponent glass forming systems with a high thermal stability and excellent glass forming ability was found. ${ }^{6,7}$ The critical cooling rate to form these bulk metallic glasses (BMG) from the melt drops orders of magnitude compared to conventional metallic glasses. For the particular $\mathrm{Zr}_{41.2} \mathrm{Ti}_{13.8} \mathrm{Cu}_{12.5} \mathrm{Ni}_{10} \mathrm{Be}_{22.5}$ alloy critical cooling rates as low as $1 \mathrm{~K} / \mathrm{s}$ were found. ${ }^{8}$ These low cooling rates allow one to observe phase separation taking place below a miscibility gap in the undercooled liquid region, so that decomposition in the as-prepared amorphous $\mathrm{Zr}_{41.2} \mathrm{Ti}_{13.8} \mathrm{Cu}_{12.5} \mathrm{Ni}_{10} \mathrm{Be}_{22.5}$ alloy on a length scale of $50-80$ $\mathrm{nm}$ was observed earlier. ${ }^{9} 10$ This decomposition during the cooling process mainly involves the fast diffusion of Be. ${ }^{11}$

In this letter, we will show that primary crystallization of the amorphous $\mathrm{Zr}_{41.2} \mathrm{Ti}_{13.8} \mathrm{Cu}_{12.5} \mathrm{Ni}_{10} \mathrm{Be}_{22.5}$ alloy reheated into the supercooled liquid involves a decomposition process. Phase separation with respect to slower moving species determines the time scale of the primary crystallization in the

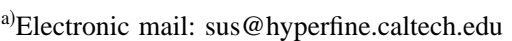

supercooled liquid. The formation of nanocrystals during isothermal annealing of the $\mathrm{Zr}_{41.2} \mathrm{Ti}_{13.8} \mathrm{Cu}_{12.5} \mathrm{Ni}_{10} \mathrm{Be}_{22.5}$ alloy has been investigated by small angle neutron scattering (SANS), transmission electron microscopy (TEM), and differential scanning calorimetry (DSC). The results from these studies suggest a decomposition process on a length scale of 13.7 $\mathrm{nm}$ preceding the primary crystallization of this alloy when annealed at $623 \mathrm{~K}$.

Amorphous samples were prepared from a mixture of the pure elements by induction melting on a water-cooled silver boat under $\mathrm{Ti}$ gettered $\mathrm{Ar}$ atmosphere. The $\mathrm{Zr}_{41.2} \mathrm{Ti}_{13.8} \mathrm{Cu}_{12.5} \mathrm{Ni}_{10} \mathrm{Be}_{22.5}$ ingots were remelted in a silica tube with an inner diameter of $10 \mathrm{~mm}$ and then water quenched with a cooling rate of about $10 \mathrm{~K} / \mathrm{s}$. For the SANS measurements, disks cut from these rods with a thickness of $2.7 \mathrm{~mm}$ were annealed at $623 \mathrm{~K}$ for different times. At this temperature, the samples are in the supercooled liquid state. ${ }^{11}$ The SANS measurements were carried out at the Intense Pulsed Neutron Source, Argonne National Laboratory. The measured q-vector range was $0.05 \mathrm{~nm}^{-1}<q<2.5 \mathrm{~nm}^{-1}$. The TEM samples were cut from the annealed disks and electrolytically thinned in a solution of $10 \%$ perchloric acid in methanol or prepared by thinsection microtomy. For the DSC experiments a Perkin Elmer DSC 7 calorimeter was used.

Figure 1 shows small-angle neutron scattering data of an as-prepared sample and of samples isothermally aged for different times at $623 \mathrm{~K}$. While the curves for the as-prepared sample and the one annealed for $80 \mathrm{~min}$ (not shown) only exhibits background scattering, a broad maximum appears for samples aged for 100, 140, and $300 \mathrm{~min}$. These interference peaks with a maximum intensity at about $q=0.46 \mathrm{~nm}^{-1}$ arise from a spatially periodic fluctuation 


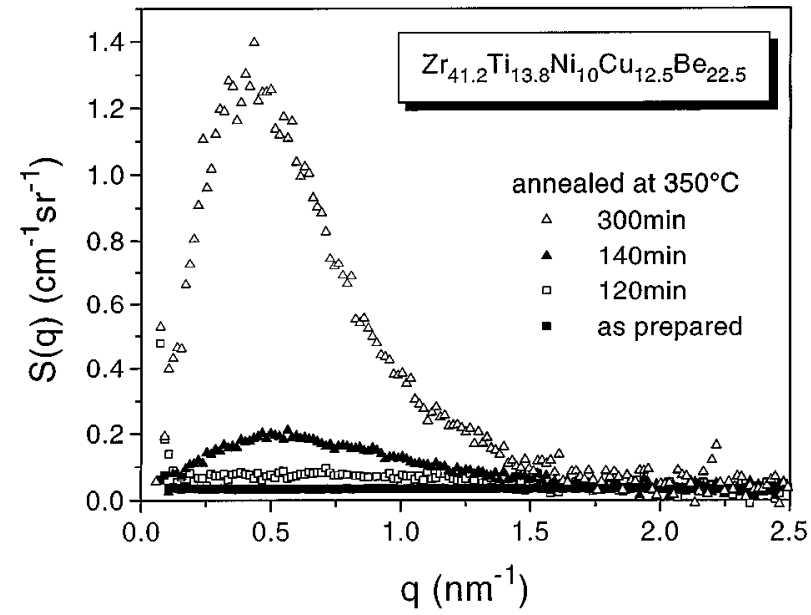

FIG. 1. SANS data of an as-prepared amorphous $\mathrm{Zr}_{41.2} \mathrm{Ti}_{13.8} \mathrm{Cu}_{12.5} \mathrm{Ni}_{10} \mathrm{Be}_{22.5}$ alloy and of samples annealed for 100, 140, and $300 \mathrm{~min}$ at $623 \mathrm{~K}$

of the scattering length density in the $\mathrm{Zr}_{41.2} \mathrm{Ti}_{13.8} \mathrm{Cu}_{12.5} \mathrm{Ni}_{10} \mathrm{Be}_{22.5}$ alloy. The wavelength corresponding to the intensity maxima does not change significantly with annealing time during the early stages of crystal growth, and is about $13.7 \mathrm{~nm}$. Guinier analysis shows that the radius of gyration increases with the annealing time from about $1 \mathrm{~nm}$ for the sample aged for $100 \mathrm{~min}$ to $2.16 \mathrm{~nm}$ after an annealing time of $300 \mathrm{~min}$.

Figure 2 illustrates a TEM dark field image (a) of a sample annealed for $300 \mathrm{~min}$ at $623 \mathrm{~K}$. Compared to the dark field image of an as-prepared amorphous sample, ${ }^{12}$ it shows a different coarser structure. The second inner ring of the diffraction pattern (b) of this sample is slightly sharper and the pattern contains two more outer-diffraction rings than a diffraction pattern of an as-prepared sample. ${ }^{12}$ These features reveal the presence of nanocrystals embedded in an amorphous matrix after annealing. The high resolution image (c) depicts one of the fcc nanocrystals that is viewed along a $\langle 110\rangle$ direction. The (111) $d$-spacing is $0.23 \mathrm{~nm}$, which corresponds to a lattice constant of about $0.4 \mathrm{~nm}$.

The most striking results from the present study are the existence of an incubation time for crystallization and the periodic arrangement of the nanocrystals. Precipitates formed by a homogeneous nucleation process are usually distributed randomly if interactions between the particles can be neglected. Since, in our case, the nanocrystalline precipitates form in the supercooled liquid, elastic interactions between the nanocrystals causing a narrow size and distance distribution can be ruled out. ${ }^{13}$ Heterogeneous nucleation of crystalline phases only leads to a periodic arrangement of the nuclei, if the nucleation sites are arranged periodically. Thus, a preceding chemical decomposition is likely to be responsible for the periodic arrangement of the nanocrystals. During the incubation time a composition wave with growing amplitude leads to a spatially periodic variation of the crystallization temperature $T_{x} \cdot{ }^{9}$ Finally, the formation of a crystalline phase starts polymorphously if $T_{x}$ drops down to the annealing temperature in the regions with the lowest $T_{x}$.

The formation of nanocrystals after an incubation time
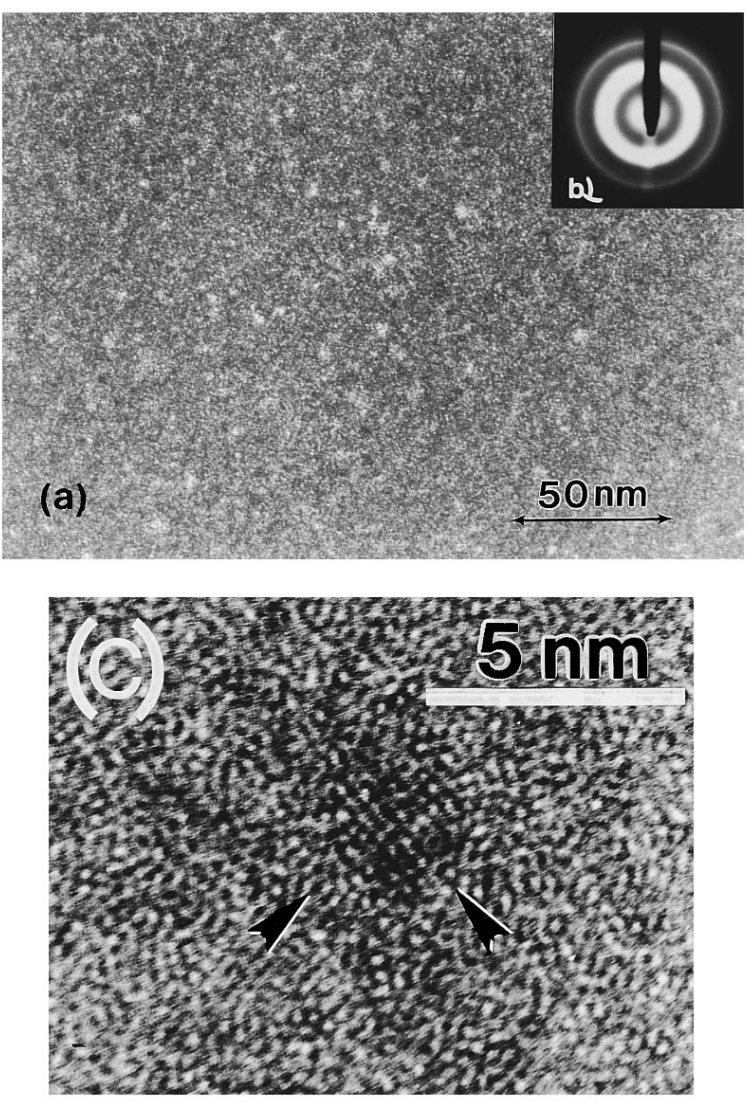

FIG. 2. TEM images: (a) dark field image and (b) diffraction pattern of a sample heat treated for $300 \mathrm{~min}$ at $623 \mathrm{~K}$, (c) high resolution image of a nanocrystal formed during primary crystallization.

of about 100 min observed in the TEM, was also monitored by DSC experiments. The DSC scans in Fig. 3 show the different stages of crystallization. The DSC curves of an asprepared sample and of the one annealed at $623 \mathrm{~K}$ for $80 \mathrm{~min}$ are only slightly different, but a significant change is observed after annealing at $623 \mathrm{~K}$ for $100 \mathrm{~min}$. The first crystallization peak at about $723 \mathrm{~K}$ decreases, while another

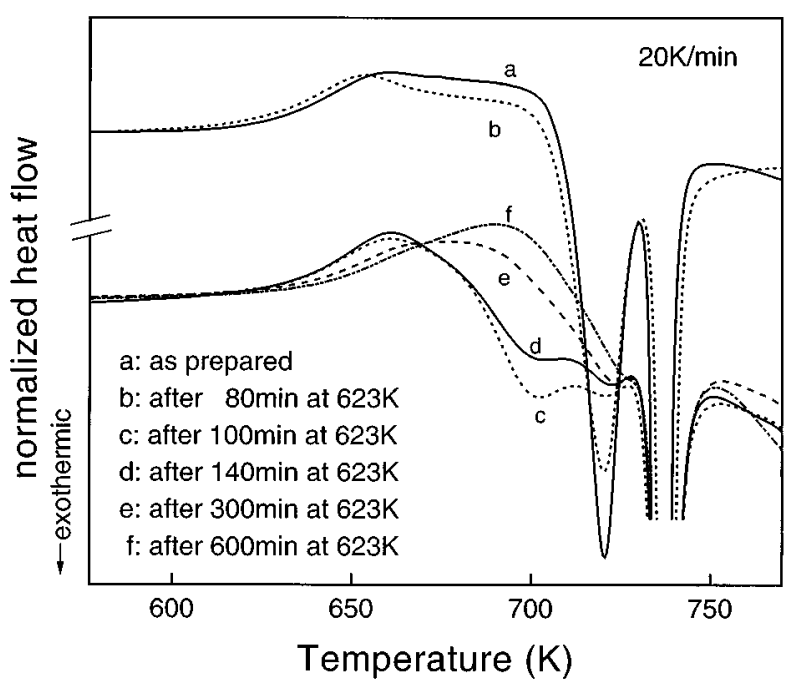

FIG. 3. DSC measurements of $\mathrm{Zr}_{41.2} \mathrm{Ti}_{13.8} \mathrm{Cu}_{12.5} \mathrm{Ni}_{10} \mathrm{Be}_{22.5}$ samples heat treated for different times at $623 \mathrm{~K}$. 
broad exothermic peak forms at about $700 \mathrm{~K}$. This exothermic event is related to the crystallization of regions with a lower crystallization temperature $T_{x}$. The signal is relatively broad, indicating a broad $T_{x}$ spectrum, as expected for a spatially varying composition. After $140 \mathrm{~min}$ annealing duration, less crystalline nuclei are formed during the DSC scan, and after 300 and 600 min no further nucleation but only grain growth occurs. ${ }^{14}$ According to the extent of formation of nanocrystals during isothermal annealing the first crystallization peak of the as-prepared alloy disappears. Additionally, for the late annealing stages, the glass transition in the noncrystallized regions broadens and its midpoint temperature shifts to higher values.

The x-ray diffraction pattern of samples which are isothermally annealed at $623 \mathrm{~K}$ for a duration longer than 100 min reveals the formation of a metastable simple fcc $\mathrm{Cu}-\mathrm{Ti}$ phase. ${ }^{15}$ Its lattice parameter is $a=0.40 \mathrm{~nm}$. The formation of a metastable compositionally invariant $\mathrm{Cu}-\mathrm{Ti}$ fcc phase has been observed earlier for cooling experiments from the melt in the $\mathrm{Cu}-\mathrm{Ti}$ and $\mathrm{Cu}-\mathrm{Ti}-\mathrm{Zr}$ alloy systems. ${ }^{16}$ Woychik et al. determined this particular lattice constant for nanocrystals with a composition of $\mathrm{Cu}_{85} \mathrm{Ti}_{15}{ }^{16}$ For longer times and/or higher annealing temperatures, a Laves phase having the hcp " $\mathrm{MgZn}_{2}$-type" structure appears. Its lattice constants are $a=0.515$ and $c=0.842 \mathrm{~nm} .{ }^{17,18}$ Although the Laves phase contains all of the components of the alloy except a lower nominal Be concentration at low temperatures, the metastable $\mathrm{Cu}-\mathrm{Ti}$ fcc phase forms first. The reason might be a smaller unit cell compared to the Laves phase and a short range atomic order that is closer to that of the undercooled liquid. An upper limit for the critical nucleus of the fcc phase is $1 \mathrm{~nm}$ resulting from the SANS data. The growth rate of these crystals is restricted, probably due to a lower mobility of the $\mathrm{Cu}$ atoms compared to $\mathrm{Be}$ atoms at $623 \mathrm{~K} .{ }^{11}$ Because the crystallization temperature decreases strongly with increasing $\mathrm{Cu}$ concentration, the primary crystallization starts in the $\mathrm{Cu}$-rich areas of the decomposed sample.

Since the SANS data of as-prepared $\mathrm{Zr}_{41.2} \mathrm{Ti}_{13} \mathrm{Cu}_{12.5} \mathrm{Ni}_{10} \mathrm{Be}_{22.5}$ samples show only diffuse background scattering, there is no indication of the above mentioned phase separation involving Be on a $50-80 \mathrm{~nm}$ scale. Most likely, the lack of any enhanced scattering contrast is related to very similar atomic densities of the amorphous decomposed regions and to the small difference in scattering lengths of $\mathrm{Zr}$ and $\mathrm{Be}$ atoms for thermal neutrons. ${ }^{19}$ Therefore, the onset of the interference signals of annealed samples must be related to an additional periodic composition variation of one of the other elements. The scattering contrast for periodic changes in the $\mathrm{Cu}$ concentration is moderate because of the similar scattering lengths of $\mathrm{Zr}, \mathrm{Be}, \mathrm{Ni}$, and $\mathrm{Cu}$. Since the Ti concentration seems to be unchanged compared to the original amorphous alloy, there is no signifi- cant increase in the scattering signal during the incubation time. We believe that the onset of the scattering signal is caused by a larger atomic density of the $\mathrm{Cu}$-Ti nanocrystals. According to this interpretation, $\mathrm{Zr}, \mathrm{Ni}$, and $\mathrm{Be}$ rich amorphous areas form during decomposition. These regions have higher glass transition and crystallization temperatures and probably show composition gradients, expressed, for example, in a broad glass transition region depicted in DSC measurements.

In conclusion, the primary crystallization in the $\mathrm{Zr}_{41.2} \mathrm{Ti}_{13.8} \mathrm{Cu}_{12.5} \mathrm{Ni}_{10} \mathrm{Be}_{22.5}$ alloy during isothermal annealing at the glass transition temperature results in the formation of spatially periodical arranged $\mathrm{Cu}-\mathrm{Ti}$ rich nanocrystals. We propose that this arrangement is preceded by a modulated chemical decomposition process. This decomposition does not only involve the mobility of Be which was previously observed. The time scale for the phase separation and the subsequent primary crystallization is determined by the mobility of the slower moving $\mathrm{Cu}$ species.

We gratefully acknowledge stimulating discussions with U. Geyer, R. Busch, and K. Samwer. The authors also like to thank C. M. Garland for her valuable assistance at the TEM and A. Peker, X. F. Sun, and D. Wozniak for their help. This work was supported by the Department of Energy (Grant No. DE-FG03-86ER45242). It has also benefited from the use of IPNS, which is funded by U.S. DOE, under Contract No. W-31-109-ENG-38 to the University of Chicago.

${ }^{1}$ L. E. Tanner and R. Ray, Scr. Metall. 14, 657 (1980).

${ }^{2}$ U. Köster and J. Meinhardt, Mater. Sci. Eng. A 178, 271 (1994).

${ }^{3}$ R. Suzuki, K. Shibue, K. Osamura, P. H. Shingu, and Y. Murakami, J. Mater. Sci. Lett. 1, 127 (1982).

${ }^{4}$ P. J. Desré, T. Itami, and I. Ansara, Z. Metallkd. 84, 185 (1993).

${ }^{5}$ A. L. Greer, Nature 366, 6453 (1993).

${ }^{6}$ A. Inoue, T. Zhang, and T. Masumoto, Mater. Trans. JIM 31, 177 (1990).

${ }^{7}$ A. Peker and W. L. Johnson, Appl. Phys. Lett. 63, 2342 (1993).

${ }^{8}$ Y. J. Kim, R. Busch, W. L. Johnson, A. J. Rulison, and W. K. Rhim, Appl. Phys. Lett. 65, 2136 (1994).

${ }^{9}$ R. Busch, S. Schneider, A. Peker, and W. L. Johnson, Appl. Phys. Lett. 67, (1995).

${ }^{10}$ R. Busch, Y. J. Kim, W. L. Johnson, A. J. Rulison, W. K. Rhim, and D. Isheim, Appl. Phys. Lett. 66, 3111 (1995).

${ }^{11}$ U. Geyer, S. Schneider, W. L. Johnson, Y. Qiu T. A. Tombrello, and M. P. Macht, Phys. Rev. Lett. 75, 2364 (1995).

${ }^{12}$ S. Schneider, U. Geyer, P. Thiyagarajan, R. Busch, R. Schulz, K. Samwer, and W. L. Johnson, Mater. Sci. Forum (in press).

${ }^{13}$ W. C. Johnson, Acta Metall. 32, 465 (1984).

${ }^{14}$ L. C. Chen and F. Spaepen, J. Appl. Phys. 69, 679 (1990).

${ }^{15} \mathrm{H}$. Fecht and S. Klose (private communication).

${ }^{16}$ C. G. Woychik and T. B. Massalski, in Proceedings of the 5th International Conference on Rapidly Quenched Metals, Würzburg, Sept. 1984, edited by S. Steeb and H. Warlimont, Vol. 1, p. 207.

${ }^{17}$ V. V. Molokanov, V. N. Chebotnikov, and Yu. K. Kovneristyi, Inorg. Mater. 25, 46 (1989).

${ }^{18}$ X. H. Lin and W. L. Johnson, J. Appl. Phys. 78, 6514 (1995).

${ }^{19}$ S. F. Mughabghab, M. Divadeonam, and N. E. Holden, Neutron Cross Sections (Academic, New York, 1981). 